\title{
Leveraging Limited Research and Development (R\&D) Resources in the Public Sector
}

\author{
Michael Senglaub, Ph.D. \\ Sandia National Laboratories \\ PO Box 5800 MS 0475 \\ Albuquerque, NM 87185 \\ $\mathbf{5 0 5 . 8 4 4 . 9 2 4 4}$ \\ 505.844 .4756 \\ mesengl@sandia.gov
}

\begin{abstract}
Mission-directed public-sector research facilities are experiencing increasingly severe budget environments while seeing expanding missions and responsibilities. In an effort to identify research leveraging methodologies an information search was conducted in conjunction with some efforts to find the proper links to systems engineering fundamentals. The result is an initial model for use in a preconcept/phase-1 engineering design organization, with a goal of improving the organizations performance.
\end{abstract}

\section{BACKGROUND}

The intent of this survey is to address emerging issues related to public sector research and development (R\&D). A number of: these issues are externally derived/such as the emphasis on dual use teckinologies and improved cost effectiveness, white others ote internally derived. At Sandia National Laboratories (SNL) these internally generated issues include fifortening wegion system development tinte. greater emphassis on simulation as well as. integrating fommercial and/or professional 8 /stems / engineering standards into SNL actrvities. At the same time the SNL is faced with.significant reductions in money designated for research.

As a nation in debt public sector R\&D cannot afford duplication or spend inordinate amounts of money on minor, minimal valueadded public research. On the other hand, we also cannot afford to terminate activities that are imperative to ensure a viable competitive national future. We need to identify techniques that improve therefficiency and effectiveness of the research dollar as well as enhance the utilify of the research being pursued. We need to minke certain that we are solving regi, high value, oublic sector technical probiems.

The sections that follow reflect a consensus of techingures and issues that have been identified in the fiterature as enhancements to the "research-to-produict" cycle. The private sector has operated in a constrained R\&D environnewit far longer than the public sector his, and is a result has identified means for leveraging the research dollars spent by a eopporation. Recognizing that survival depends on "new product" and "efficiency of effort" the private sector has devleoped useful approaches for leveraging effort. A bibliography has been included in additiona to references.

\section{CONSENSUS MODEL}

There appear to be several overriding elements associated with the transfer of technology in organizations which are efficient at this transition of research to product. The elements consist of (1) detailed technology "roadmaps" or plans, (2) a technology analy- 


\section{DISCLAMIER}

Portions of this document may be illegible in electronic image products. Images are produced from the best available original document. 
sis capability, (3) decision theory, and (4) organizations optimized for R\&D transitioning. A fifth element which appears to be pervasive in the literature is the idea of a $R \& D$ technology portfolio. The portfolio is an attempt to balance the research activities among, basic, applied, and process directed research activities.

\section{Technical Roadmaps or Plans}

There is a consensous expressed in the literature that it is important to develop "strategic plans or roadmaps." These plans are detailed technical management and planning documents used in the evaluation and control of technical research programs. Motorola (Willyard, 1987) implemented a parallel planning structure which employs two types of plans: the Emerging Technology Roadmap and the Product Technology Roadmap. The first roadmap emphasizes a single technology and examines Motorola's capability. in that area, its relationship to competitors" capabilities, and provides forecasts for progress in a technology. The Product Roadmap is broader in scope and a vorreal plan consists of eight documents proviting a comprehensive evaluation of a prodinct line over time. The eight documents Consist. of (1) a description of the business, (2) the business mission, (3) strategies. (4) mariet share, (5) sales history and marke share, (6) life cycle curves, (t) product plans, and (8) experience curves. Tiese plans axe intended to encourage the use of advanced analysis and planning techniques to for making R\&D allocation decisions.

\section{Technical Analysis}

Van Wyks' (1990) discusses a concept which he calls technology analysis. This methodology is used to support the development of technology roadmaps and portfolios. The paper describes five basic evaluation metrics:
(1) a technology protocol, (2) a classification mechanism, (3) technological trends, (4) technological limits, and (5) a profile of social preferences. The technology protocol, trends, and limits seem to be well suited for use in the broader technological analysis program of a public sector research organization.

A methodology of greater scope and fidelity seems to be an approach proposed by Clarke (1973). This model, developed at the Office of Research Analyses.(ORA), is intended to (1) provide information to assist in insuring that a project/s relevant to an organizations mission; ara (2) develop methods for identifying mission relevalu research opportunities. The approach is apeealing because of its. synergy with the systems engineering frutctions associated with preconcept design and analysis activities. The principle elements of the model are mission analysis, systems analysts: and research analysis. The relationships and outputs of the analysis actrvilussâre shown in Figure 1.

In the context of Clarke's paper, systems analysis provides cost effectiveness evaluations for system concepts which are founded in certain technologies. As part of this analysis, technical barriers are identified which need to be overcome in order for a system concept to be developed. The research analysis aspect identifies ways for translating a technical barrier into a research opportunity. The model suggests that research analysis be employed to develop promising system concepts based on the projected technologies and provide research objectives. 


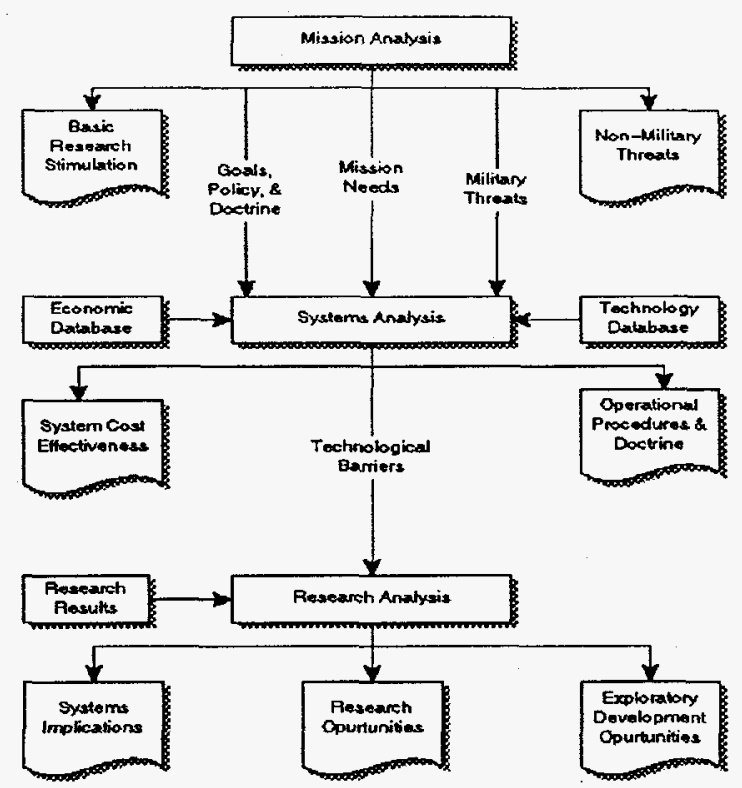

Figure 1. Relationship of technical analysis elements.

\section{Selection Criteria}

What appears to be endemic inthe literature is a broad scope of selection criteria for use in identifying the R\&D projects for funding. The best advice seems 10 be that itute selection criteria neodsto be tallored to the mission of the institution. The critentureed to represent the importance. of the various branches of ar. organization, wititing, production, and $R \&$ \&. In studies conducted in Japan (Sakakura, 1991), it/was found that there is a higher probutifitity of success if both management and the researcher are involved in planning from the outset. The point is that criteria need to be established, and R\&D projects should be selected based on the criteria(Szakonyi, 1990-J).

Souder (1980) concluded that as part of a selection criteria large projects needed to be broken into a number of smaller projects.
His data demonstrated that $72 \%$ of projects involving more than seven people experiencedsignificant interface problems while only $44 \%$ of projects with less than seven people experienced the same problems. He further found that projects with significant problems about half were partial or complete comercial failures. He grouped R\&D/Marketing interface problems into four categories: (1) lack of communication, (2) lack of appreciation, (3) distrust, and (4) too-good friends. This last category seems to be characterized as too much harmony.

Cetron (1973) ditineated 30 decision methodologies in his atticle for use in R\&D projectselection and kincluded references for moder details. The teelaniques range from operations research utility theory to economie analysis techniques. In this article Cetrofititentified 15 features which could be used to describe the input and output of the decision modets. Another detailed model for R\&D project selection (Kuwahara and Taked..1990) is based on a cost-effectiveness analysis methodology. These techniques should be used as starting points to develop selection methodologies and criteria which reflect the imperatives of the public research organization. The likelihood is that each organization, upon reflection and analysis, will find a unique set of selection criteria.

\section{Organizational Issues}

There appears to be a significant communications component in R\&D activities. Communication must be maintained among all elements of the organization, including manufacturing, marketing, and researchers involved in other projects. There also seems to be a consensus that project management planning activities needs to be formalized in the R\&D organization. The planning provides the $R \& D$ organization with goals and objectives enabling the organization to 
define performance metrics. These metrics can be used to ensure that the effort is not a dead-end technology search. The planning and control, however, must recognize the risk associated with research and should be less constrained than in other parts of an organization. Plans can be ignored, however, Souder (1980) countered this argument was found in Souder's paper (Souder, 1980) when he found that successful projects were headed by "tough-minded individuals" who would, when necessary, "knock some heads" together to overcome roadblocks.

Lack of proper R\&D management skills can lead to organizational inefficiencies. Szakonyi (1990-J) indicated that R\&D management possesses unique problems: there needs to be a balance in planning and control, management must reflect corporate goals, to emphasize communication, develop effective evaluation mechanism that exhibits a high degree of integrity, and is heavily people ori ented. He felt that "some R\&D managers should not be managers." Rather they should have been promoted along a separate technical ladder.

There was some discussion in the liferature regarding the aspects of creating effect ix teams. There appeared to be on implicit understanding that a teann consists. of engineers and researchers that bring uinique skills and tin vinderstanding of the relationship of these skiltis to the project as a whole. Sakakura (1991) foud that projects had a higher probability of suceess in organizations that selected its \%team members and which possessed a broad base of expertise.

Sakakura (1991) also indicated that success was more likely when researchers were given the opportunity to conduct parallel research in basic and applied fields. Szakonyi(1990-J) indicated that engaging $R \& D$ people in technically challenging work will enhance the organizational effectiveness. Finally, methods need to be identified which tap the wealth of ideas regarding innovations which far too often remain unnoticed.

In a second paper, Szakonyi (1990-N) discusses the need for high levels of interaction with the customer. He points out that R\&D organizations traditionally think that its' operations units are the customer of their efforts when in reality they are the ultimate users of the companies products. Szakonyi strongly recommends that $R \& D$ personnel interact with thetechnical staff of their industrial customers. casting activities oe utilized in an R\&D organizafion with inferaction from the custome concerning future needs. This role is traiditionally the markeing department's Fole but signiffcant and important input can be provicled through this level of interaction.

W. Mackey (1995) presented a paper at the 1995 St. IFouis NCOSE Symposium, on technology management. This paper explores the area of incorporating technology into an organizations mission and projects while this article is exploring techniques for pulling research in a direction to solve an organizations future problems. There is a significant number of interesting ideas in Mackay's paper which is relevant to the later problem.

Mackey identifies eight overriding strategic elements which comprise technology management. The elements he identified are (1) technology management requirements, (2) technology readiness levels, (3) technology brokering, (4) project management commitments, (5) a technology evaluation and adaptation methodology, (6) prototypes, (7) selected implementation, and (8) lessons learned. This breakdown seems to compliment Van Wyk's (1990) breakdown. The more interesting aspect of Mackey's paper is 
the six stages associated with technical management: (1) contact, (2) awareness, (3) understanding, (4) trial use, (5) adoption, and (6) institutionalization. This perspective on technology management could provide a very useful foundation for building a culture that adapts and uses new technologies in the solution of current or near-term problems. There are also elements of this model that are useful in research leveraging.

\section{RECCOMMENDATIONS}

The literature provided some interesting initial approaches for leveraging the public sector research dollar. There appear to be four basic elements needed in a high-performance preconcept organization: (1) analysis maturity, (2) decision methodologies and metrics, (3) technical roadmaps, and (4) an organizational structure with good business practices. The following sections will delineate examples of these four elements and provide argu ments indicating the achievement of the goals and objectives discussed in the opening of this article.

\section{Relationship to Systems Engineering}

A common principle found w most of articles indicated, either explicitiy. itly, the importance of analysis actirities in organizations 4 ith effective tesearch fransistioning processes. A detailed examination of these analysis artivities revelils significant overlap with systeris sengineering functionality. The exception is the idea of research analysis discussed in Clarkke's (1973) paper. Figure 2 provides a process flow diagram for identifying technologies which could solve problems of national scope in the public sector.

The model presented in this paper is based on the systems engineering paradigm, and further discussion will use the appropriate terminologies. As is typical of systems engineering activities, specifically trade-studies, the process is iterative in nature. The drivers of the process include databases of new technologies, future missions, and operational environments that impose constraints or opportunities for advanced technology solutions. The heart of the process involves systems analysis activities with an objective of defining technological-based solution architectures, research project metrics, and goals for a research area or project. This information is then processed to produce technological roadmaps andiresearch portfolios.

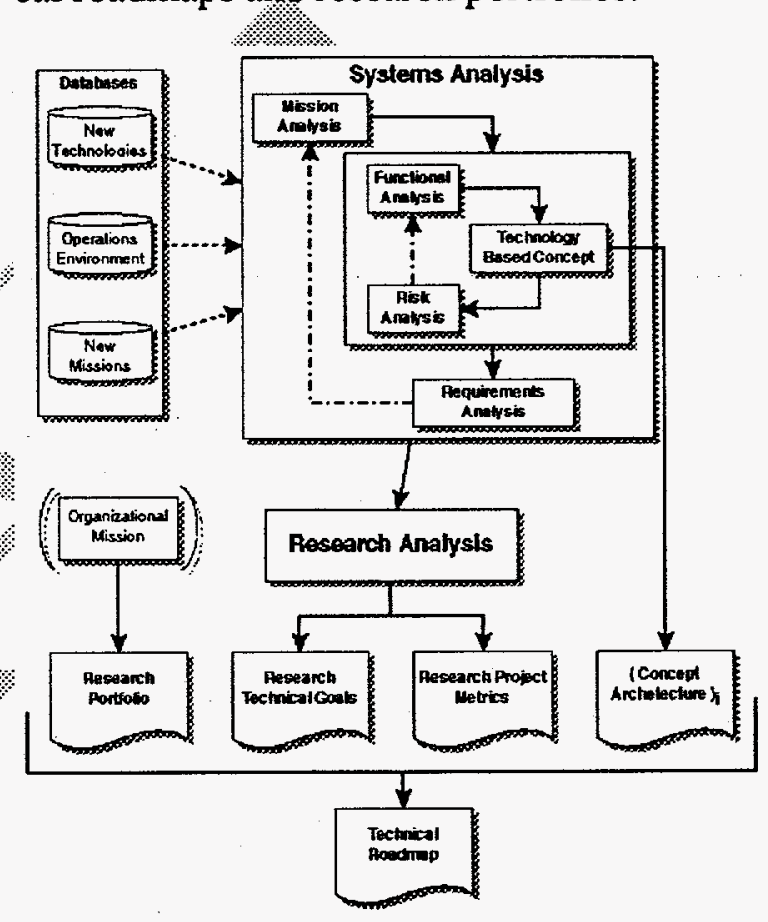

Figure 2. Process chart for research transitioning organization.

Databases The databases in this model are the result of an active ongoing data-gathering process. The systems engineer involved in this activity needs to allocate significant amounts of time to become familiar with research being pursued by the organization the systems engineer also needs to be cogni- 
zant of research at other facilities, universities, and in the private sector. This information should be captured in a database for use with case-based reasoning tools so a broad spectrum of engineers and researchers can easily gain access to the information. Sary \& Mackey (1995) presented a paper in which a case-based reasoning tool was used in a lessons learned activity at NASA. Casebased reasoning is a type of expert system which enhances the application of past experience to new problems. It uses databases and natural language queries for storage and retrieval with the expert system providing assessments on the applicability of the information to the new problem.

Another needed database requires the engineer to be in communication with customer organizations involved in future endeavors. There need to be assessments of the types of problems organizations will be faced with in the future. Typically, mission projections possess implicit technological assumptions which need to be identified by the systems engineering organization for use in driving or pulling research. This information, along with the operational databases, which consist of social, economic, and political projects, provides the basis for all rentuning actw? ties.

Systems Analysis Systems atialysis supports the mission atuasis, requirements analysis, functional analysis risk analysis, and the technology concept. generation activities. These analyses, which iseed to be iteratively applied are expected to produce solutions to a mission need using a specific technology or combination of technologies. The analyses would typically be at a relatively high level or a level that would expose technology specific requirements. Systems analysis actions would consist of:

- Identify system level and subsystem response or performance functions.

- Perform sensitivity analyses to identify subsystem requirements.

- Conduct two levels of cost analysis; (1) based on the risk analysis assess cost to overcome technological barriers, and (2) if possible, assess the cost of using a technology in a system concept.

- Functional architectures need to be defined which employ specific technical solutions.

Mission Analysit Mission analysis consists of problem ifentification and appropriate solution responses. . For example, in the weapons arena, recogitzing a new conventional threat and identifying systems, tactics or procedures which can zinitigate the effect of the threat are appropriate applications of mission analysis. The analysis activity is commonty identified with weapons design but is equally stuited for other design efforts.

Risk Requîrements Analysis Requirements and risk analysis provide the foundation of information for technological assessments. Requirements analysis is the first step in the development of research goals. Identifying the levels of subsystem performance required for a system to meet mission requirements enables the systems engineer, in conjunction with a researcher, to establish goals for the activity. The risk analysis activity must honestly address all potential obstacles that could mitigate successful development of a technology. The ultimate objective is to develop goals for a research project and the currently perceived limitations which need to be overcome in order for the technology to become a viable design alternative.

Research Analysis Research analysis is defined as the identification of mission relevant research opportunities of on-going or 
projected research projects. The objectives of this analysis activity are to determine the appropriateness of the research within the organizational mission and to formalize the system context of the technology. It is also an objective to assess the technological risk factors in a process of down selecting technological paths which potentially will fail. The analysis comprises a fine balance between recognizing a high-risk activity with legitimate payoff and a project of limited value.

The information generated as a result of these analyses consists of technology based design concepts, research metrics, and research goals. Identifying a technology that can be applied to solving a public sector problem will in general result in specific and possibly unique system architectures. These system architectures are archived for future use and used in follow-on analyses to establish requirements. The requirements identis fied for an architecture need to be transformed into research goals for the relevant technology. Finally the research metrics reflect the importance and iverevance to organizational mission of each lesearch project and or proposal. \%antinformation is then transformed into the technicalkroadinaps for future developmentsactivities:

Suggested Public Sector Tecinical Roadmaps

A reccommended technical/roadmap, in a public sector R\&D civironment, should address the following elements:

- Mission definition in a system context and its relation to the organization's mission and research portfolio.

- Technology goals.

- Technology limits, how much is achievable.

- Technology trends, techniques similar to cost estimation need to be used to predict trends.

- Risk mitigation plans. High risk show stoppers need to be addressed first to assess future viability and support.

- Cost and economic analyses.

- Technological architectures for use in future development activities.

\section{Business Practices}

Organization Soufer (1980) discussed the concept of "new product committees" which reviewed strategte. plans, policy issues and unresolved Eeonfliets. The committee memberships. would shift as the R\&D effort matufed. This concept ainght be modified to act as the focal points for marketing solutions to mainy of today's public sector problems. Small teams could be formed comprising the systems engineering house, the researcisirea and the program sector to 9romote a technological solution. More than ever. of fore, as engineers we need to promote and market the correct solutions to problems. The solutions being generated by politicians and lawyers exhibit a significant lack of problem solving skill and insight.

Portfolio A number of authors discuss the idea of research portfolios, which are the result of decisions made regarding projects. The portfolio is based on organization mission and the results of the analysis activities discussed previously. Allio (1984) breaks research into eight generic categories: (1) exploratory research, (2) new product, (3) product extension, (4) process improvement, (5) raw material substitution, (6) regulatory response, (7) energy saving, and (8) diversification. All of these areas, except possibly diversification, have direct correlation with mission related activities at SNL. The corporate task is to identify levels for each area appropriate to formulate a balanced and opti- 
mized portfolio of research activities.. The new operational environment requires that research organizations exercise a high degree of control, as Millett (1990) says "...he who pays the bill for technical R\&D gets to set the goals."

Accounting There appears to be a rather global move to use cost-based accounting in business and industry, particularly in the research areas. It appears that industry is extremely concerned with identifying and mitigating low "return on investment" (ROI) alternatives and accurately allocating overhead costs. This may become more important in public sector research in order to better assess cost-benefit metrics of programs.

\section{NEEDS VALIDATION}

\section{Systems Engineering}

Adoption of professional systems engineer ing standards can be a costly and cathartic endeavor for an organization; therefore, a graded implementation of systemisengineering possesses a few advantages. It vables the development of metrics tor use in ustifying the expense and effort of a booter implementation. The required sistl set is a subset of a full sostems ergineering implementation. Figure 2 showed activities and skills requirad for the analysis activities. The systems engineering subset of elements consists of mission. functiónal, risk, and requirements analysis, aloitg with rudimentary sythesis and a research analysis function. The secondary aspect of working with this limited set of systems engineering skills is the level of detail required. The nature of preconcept type activities does not require the rigor and detail needed in concept development activities. A strength of this approach is the leveraging potential of these activities in an organization.

\section{Information/Communication}

Information along with a robust communications component are key to the successful application of systems engineering rigor in a preconcept organization. The information gathering element and communication linkages need to be strengthened and extended at public sector research facilities. Missions have often precluded the ability to freely interact with diverse individuals and organizations and has resulted in feudal states of information. The links need to extend from systems engineering organizations, research organizationsto to isstomer planning organizations. The information gathering and assimilation process needs to possess a methodology for conimunicating and arehiving the information gathered in this open environment. Databases used in conjunction with case-based reasoning tools may proxide the mechanism for retaining and disseminating the information.

\section{Develobifient Time}

In order to reduce overall life cycle costs of systems increased emphasis needs to be placed on preliminary systems engineering and analysis activities. There is also a need to shorten the product cycle times. These goals may be in conflict, especially for a fledgling systems engineering organization. If we can improve the direction and control of mission relevant research we may be able to reduce some development times. Figure 3 shows the relationship between research and development in an organization employing sound research decision methodologies. Failing to anticipate future needs in mission related research moves the research curve to the left in the figure, effectively lengthening development times. Optimally selected research works to anticipate the problems and have solutions at hand when a technology needs to be used in a design solution. 


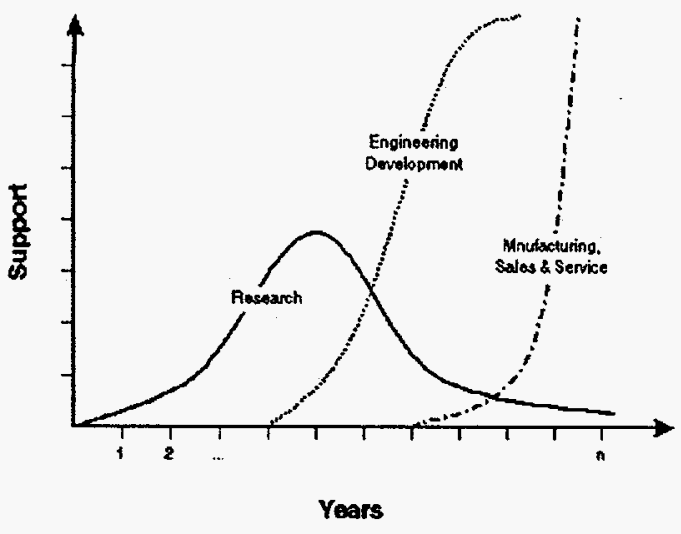

Figure 3. Phase and level of support models for research, development and production.

\section{Dual Use}

Optimizing dual use technology develop: ment and technology transfer requires that an organization needs to be looking at problems outside it's normal fields of responsibilities. Defense related missions requires: awtareness of activities at the war colleges, as well as STRATCOM the various ineater operations planning branches such as TRADU.: the Institute for Defense Analysis. Titese organizations provide us with projected needs in the weapons area. It does not proyide us with insights. Into which tectinology might prove beneficial in the privale sector. The organization also riceds to establish contact with the National Institute of Health, the Transportation Departnient, and think tanks like RAND, The National Defense University, and others.

\section{REFERENCES}

R. Allio and D. Sheehan, (1984), "Allocating R\&D Resources Effectively," Research Management, July-August,
1984, pp 14-20.

M. Cetron, J. Martino and L. Roepcke, (1973), "The Selection of R\&D Program Content--Survey of Quantitative Methods," Quantitative Decision Aiding Techniques for Research and Development, $M$. Cetron et al. eds, Gordon \& Breach, 1973, ISBN 0-677-14250-1, pp 1-10

R. Clarke, (1973), "On Relating Research Problems to Mission Requirements," Quantitative Decision Aiding Techniques for Research and Development, $M$. Cetron et al. eds. Gordon \& Breach, 1973, ISBN 0-677/4250-1, pp 63-68

Y. Kuwahara and Y. Takeda, (1990), "A Managexial Approach io Research and Development Cost-Effectueness Evaluafion," IEEE Transactions on Engineering Marnagerinent, Vol. 37, No. 2, May 1990.

W. Mackey and R. Yost, "A Systems Engineering Approach to Technology Management," Proceedings 1995 NCOSE, St. Yom:

S. Millett, (1990), “The Strategic Management of Technological R\&D: An Ideal Process for the 1990's," Int J. of Technology Management, Vol. 5 No. 2, 1990, pp 153-163.

S. Sakakura and M. Kobayashi, (1991), “ R\&D Management in Japanese Research Institutes," Research Policy 20 1991, pp 531-558.

C. Sary and W. Mackey, "A Case-Based Reasoning Approach for the Access and Reuse of Lessons Learned," Proceedings of NCOSE 1995, St. Louis.

W.E. Souder, (1980, )"Promoting an Effective R\&D / Marketing Interface," Research Management, July 1980, pp 1015.

R. Szakonyi, (1990-J)“101 Tips for Managing R\&D More Effectively - I", Research 
and Technology Management, JulyAugust $1990 \mathrm{pg}$ 31-36.

R. Szakonyi, (1990-N), “101 Tips for Managing R\&D More Effectively - II," Research and Technology Management, November-December 1990, pp 41-46.

R. Van Wyk, (1990), "Technology analysis and R\&D management," R\&D Management, 20, 3,1990, pp 257-261.

C.H. Willyard and C.W. McClees, (1987), "Motorola's Technology Roadmap Process," Research Management, SeptemberOctober, 1987, pp 13-20.

\section{Supporting References}

D. Christiansen, (1987) Engineering Excellence: Cultural and Organizational Factors, Sec 15, R. Schmitt, "Successful Corporate R\&D," IEEE PR. 1987, ISBN 0879422297, pp 133-140.

A. Frohman, (1982), "Technology as a competitive weapon," Harvard Business Review, January-February 1982, pp 97104.

R. Frumerman, (1992), "Cost-Effectye R\&D," Technovation, Volưne 12 No. 3 1992, pp 203-208.

D. Merrifield, (1976), "Basic Business Concepts for R\&Swainagement; Research Marfagement, Mrach 1976.pp 33-36.

M.F. Wolff, (198\%)."To Innovate Faster, Try the Skunk Wolles:" Research Management, September-Octobe 1987, pp 7-8.

\section{AUTHOR BIOGRAPHY}

Michael E. Senglaub has worked in a number of engineering departments at Sandia National Laboratories since 1979. Prior to that time he worked as a research engineer at Argonne National Laboratories and the Gesselshaft fuer Kernphysik (GfK) in Karlsruhe Germany. He has a Ph.D. in Engineering
Science from Northwestern University, a M.S. in Mechanical/Nuclear Engineering from the University of Texas, Austin, and a B.S. in Physics from the University of Texas, Austin. He is a member of MORS and NCOSE.

This work was supported by the United States Department of Energy under Contract DE-ACO4-

94AL85000.

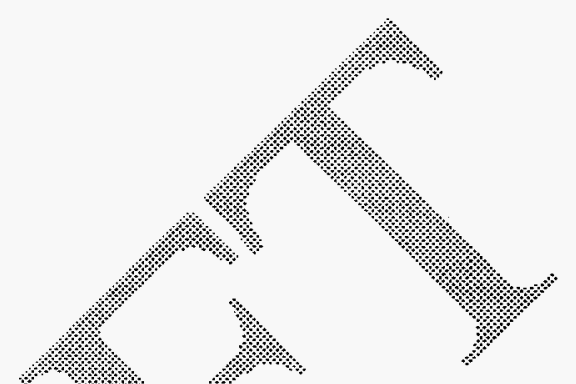

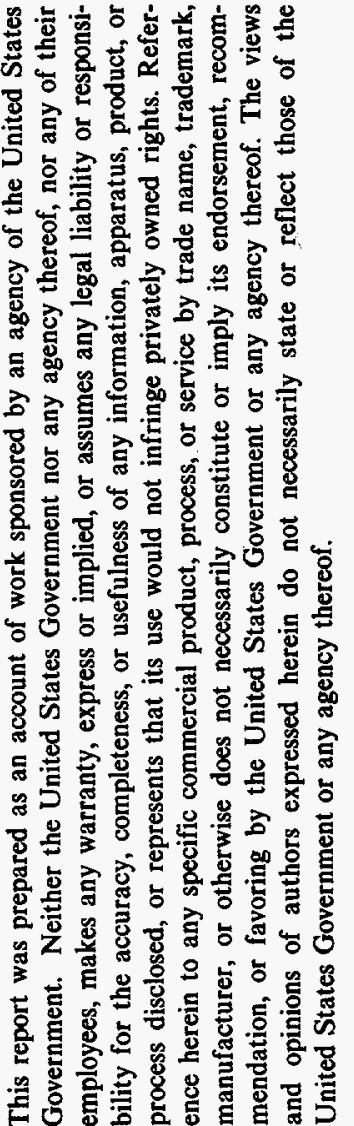

